\title{
9- O céu de Suely: o (des) encontro do ser com o lugar e consigo mesmo
}

\author{
Vanessa da Luz Oliveira ${ }^{1}$
}

\section{Resumo}

O presente trabalho tem como objeto de estudo o filme O Céu de Suely (2006), de Karim Aïnouz, se propondo a realizar uma análise sobre os processos de desterritorialização experimentados pela protagonista Hermila. A metodologia utilizada tem como base o conceito de Representações Sociais (Moscovici, 1961), partindo do pressuposto de que esse tipo de discurso se inserem categoricamente na construção de identidades sociais, aliado aos estudos da análise de conteúdo e imagem. Verificamos que a referida obra apresenta uma narrativa em que as vivências diaspóricas, ao mesmo tempo em que outros aspectos da cultura sertaneja, são mescladas e incorporadas na representação do espaço sertanejo, corroborando para a ideia de que esse processo de desenraizamento do migrante transforma sua identidade única, afetando até mesmo sua forma de enfrentar a realidade.

Palavras-chaves: Cinema. Migração. Identidade. Nordestino.

\begin{abstract}
The objective of this work is to study the film Suely's Heaven (2006) by Karim Aïnouz, proposing to carry out an analysis of the processes of deterritorialization experienced by the protagonist Hermila (Hermila Guedes). The methodology used is based on the concept of social representations (Moscovici, 1961), starting from the assumption that such representations are categorically inserted in the construction of social identities, together with the studies of content and image analysis. We verified that the cinematographic work presents a narrative in which the diasporic experiences, while other aspects of the sertanejo culture are mixed and incorporated in the representation of the sertanejo space, corroborate to the idea that this process of uprooting of the migrant transforms its identity, affecting Even your way face reality.
\end{abstract}

Keywords: Cinema. Migration. Identity. Northeast.

\section{Resumen}

El presente trabajo tiene como objeto de estudio la película El Cielo de Suely (2006), de Karim Aïnouz, proponiéndose a realizar un análisis sobre los procesos de desterritorialización experimentados por la protagonista Hermila (Hermila Guedes), La metodología utilizada tiene como base el concepto de Representaciones Sociales (Moscovici, 1961), partiendo del supuesto de que tales representaciones se insertan categóricamente en la construcción de identidades sociales, aliado a los estudios del análisis de contenido e imagen. La obra cinematográfica trae una narrativa en la que las vivencias migratorias, al mismo tiempo que otros aspectos de la cultura sertaneja son

\footnotetext{
${ }^{1}$ Possui graduação em Comunicação Social - Jornalismo em Multimeios pela Universidade do Estado da Bahia (UNEB).
} 
mezclados e incorporados en la representación del espacio sertanejo, corroboran para la idea de que ese proceso de desarraigo del migrante transforma su identidad, afectando incluso su forma de hacer frente a la realidad.

Palabras claves: Cine. Migración. Identidad. Nordestino.

\section{Introdução}

Em meados do século XIX, uma grande leva de nordestinos, fugindo da seca, partia em direção a Bahia, por causa da expansão econômica da região, devido às plantações de cacau, e, para a região Norte do país, onde a Amazônia se destacava através da exploração da borracha, que precisava e contava com um alto número de mão-de-obra, que vinham de cidades nordestinas, como Ceará, Paraíba, Pernambuco e Rio Grande do Norte (OJIMA; FUSCO, 2014). Com a expansão industrial de São Paulo, a partir dos anos de 1930, essa metrópole se tornou, então, o grande destino desses migrantes, especialmente, para a zona metropolitana e para a região do $\mathrm{ABC}$, que compreende as cidades de Santo André, São Bernardo e São Caetano do Sul, polo de grande concentração industrial. Segundo Marco Villa (2010), aos migrantes sertanejos, eram reservados os setores de trabalhos sem qualificação profissional e com salários mais baixos.

A partir da década de 1980, a região Centro-Oeste passa a despontar como destino também para os nordestinos. Os dados do censo de 2010 - referente a 2000 confirmam que São Paulo já não é o principal destino dos "retirantes sertanejos", passamos a perceber, na verdade, um efeito reverso, as migrações inter-regionais estão diminuindo, enquanto que a expressividade das migrações de retorno, o regresso a seu local de origem, assim como os deslocamentos dentro da própria região Nordeste tem aumentado, devido a uma nova configuração econômica regional que agora favorece a distribuição de água nas zonas rurais, por exemplo, como a expansão de áreas que se tornam cultiváveis devido a irrigação, ou as indústrias que se firmam nos centros urbanos. Porém, de acordo com os autores Ojima e Fusco (2014), é preciso destacar que essas migrações de retorno têm como principal destino as zonas urbanas.

Neste artigo, nos propomos a estudar como a migração e seus desdobramentos, encenados na narrativa de $O$ céu de Suely (2005), representam os processos de desterritorialização experimentados pela protagonista Hermila (Hermila Guedes). 
Entendemos que a migração é um fenômeno complexo, visto que, como argumenta Hall (2013), muitos migrantes não mais reconhecem ou se reconhecem em seu local de origem, como se os elos de pertencimento tidos como naturais tivessem sido rompidos devido as suas experiências diaspóricas. Outro fator importante também deve-se ao fato de que, apesar de ser o mesmo espaço físico, a estrutura social que havia antes dele ter partido também não é mais a mesma. A análise dessa produção cinematográfica é importante para entendermos como a representação do nordestino é mediada, textualizada, construída e imaginada no cinema, revelando através de elaborações por vezes simbólicas, no decorrer da experiência migratória da personagem, que é cercada por significados dinâmicos e complexos, nos quais ocorrem uma quebra de antigos sistemas culturais e ganham novas ressignificações das identidades dos sujeitos.

Dessa forma, entendemos o importante papel dos meios de comunicação na compreensão da formação das representações sociais, cujas principais características reside em seu modo de construção eminente coletivo. Segundo Jodelet (1991), as representações sociais são estruturas e processos de comunicação necessários a compreensão do mundo social em que vivemos, que emitem significados produzidos e transmitidos, em sua maioria, de forma consensual, através de estruturas educativas, das tradições, etc., podendo alimentar práticas culturais em vigor na sociedade, transformando-as ou perpetuando-as, legitimando poderes ou contribuindo para processos de mudança e a construção do senso comum (MOSCOVICI, 2003; JODELET, 1991 apud SANTOS; ALMEIDA, 2005). Um processo global de comunicação no qual o cinema está inserido.

Nesse contexto, a análise de conteúdo e da imagem possibilitaram o estabelecimento de uma relação das imagens fílmicas com alguns aspectos de seu contexto, como estudos sociológicos, antropológicos, psicológicos e culturais sobre a ideia de Nordeste. Para Krippendorff (1990), a análise de conteúdo pode ser compreendida como uma técnica de investigação e descrição objetiva, sistemática, que orienta a investigação fundamentalmente de caráter empírico, exploratório, vinculada a fenômenos reais e de finalidade preditiva, abrangendo as ideias de mensagem, canal, comunicação e sistema, que permite ao pesquisador planejar, comunicar e avaliar criticamente os resultados. Assim, ponderamos que as imagens que se projetam no cinema não são delineadas aleatoriamente, mas são frutos de uma escolha.

Cada elemento apresentado é concebido com o intuito de criar realidades, cada escolha de ângulo, de objetos, cores ou trilha sonora são envoltos de significação 
(MARTIN, 2003). Para Joly (1996), mesmo a imagem sendo uma linguagem universal, para analisá-la e compreende-la é necessário realizar a leitura da imagem, para isso o analista deve decifrar significações por trás de cada imagem, que transmitem uma mensagem. Portanto, se faz necessário estudar o contexto histórico, social, político, econômico e até geográfico em que está inserida a obra.

\section{Migrar é cruzamento de identidades}

O que entendemos por identidade? Para começar, segundo Silva (2000), a identidade não é fixa, ela é permanentemente produzida, e ao questioná-la, estamos tentando desestabilizar o que foi naturalizado. Como nos lembra Hall (2013), temos identidades que se adaptam no contexto social em que nos encontramos - trabalho, familiar, religiosos, escolar - e todas elas trazem consigo a incapacidade de ser una e até mesmo singular, já que são amplamente construídas ao longo de discursos, práticas e posições que, possivelmente, virão a se cruzar ou ainda se opor, em um processo constante de transformações. Para Kathryn Woodward (apud SILVA, 2000), a identidade é construída simbólica e socialmente, com o objetivo de, por exemplo, identificar nas relações sociais quem é quem. Ainda de acordo com essa autora, a construção da identidade humana requer que consideremos não somente os aspectos simbólico e social, mas também os pontos de vista envolvidos na afirmação das várias identidades que tem causas e consequências materiais.

\footnotetext{
É precisamente porque as identidades são construídas dentro e não fora do discurso que nós precisamos compreendê-las como produzidas em locais históricos e institucionais específicos, no interior de formações e práticas discursivas específicas, por estratégias e iniciativas específicas. Além disso, elas emergem no interior do jogo de modalidades específicas de poder e são, assim, mais o produto da marcação da diferença e da exclusão do que o signo de uma unidade idêntica, naturalmente construída, de uma "identidade" em seu significado tradicional - isto é, uma mesmidade que tudo inclui, uma identidade sem costuras, inteiriça, sem diferenciação interna (HALL, apud SILVA, 2000, p. 109).
}

Todos esses autores concordam que a identidade só pode ser construída a partir da relação com outro. Assim, promovendo um embate entre a diferença e a exclusão, fica claro, que o ato migratório propicia o contato com outra cultura e, por conseguinte, com outras identidades, supondo um conflito, crise e posteriormente uma adaptação aquele novo espaço, ou não, e "essas novas identidades podem ser desestabilizadas, mas também desestabilizadoras" (WOODWARD apud SILVA, 2000, p. 22). A conformação 
dessas novas identidades passa por um difícil processo de transação concernente às identidades individuais e grupais, além dos "próprios valores, envolvendo questões étnico-raciais, vivência de preconceito, educação dos filhos, relações familiares, questões intergeracionais, de gênero, enfim, uma gama de questões relativas à própria existência humana" (DANTAS, et. al., 2010, p. 50).

Ainda de acordo com Dantas (et. al., 2010), tais processos não costumam ser simples, mas permeados por conflitos e estresse psíquico. É necessário observar que, conforme exposto acima, a identidade em si é dinâmica e flexível, percebemos que a identidade do sujeito não nasce pronta e acabada, mas decorre de todas as experiências que ele ou ela vivencia no decorrer de sua vida. Sua constituição está inteiramente relacionada às representações que apreende e forma acerca do mundo, e assim, consequentemente, de si. Para Silva (2000), é através dos significados produzidos pelas e nas representações que nos posicionamos como sujeito, tornando e dando sentido aquilo que somos ou podemos vir a ser.

No Brasil, são as migrações nordestinas que ocupam maior espaço nas representações coletivas, sejam elas na literatura, nas novelas ou no cinema, e, por conseguinte no ideário popular. Muitas vezes são identidades que perdem suas individualidades, sendo apagadas de forma pejorativa através de adjetivos empostados aos migrantes, assim passam a ser chamados de "nortistas", "nordestinos", "baianos", “paraíbas”. Outro elemento importante nesta análise é a percepção de que, em sua grande maioria, o migrante nordestino aparece sempre associado à seca, essa que, por sua vez, funciona como unidade estrutural de narrativas, agregando aspectos ao cenário e aos personagens., como veremos a seguir.

\section{O migrante nordestino na literatura e no cinema}

A relação entre a seca e migração se faz presente mesmo em obras, onde o espaço não seja mais o sertão nordestino, cujos enredos se passem, por exemplo, no Rio de Janeiro, como é o caso da obra "A hora da estrela" (1977), de Clarice Lispector. Entre as obras mais conhecidas que tratam do tema migração e Nordeste, podemos citar "O quinze" (1930), de Raquel de Queiroz, que narra sob o ponto de vista de seus personagens, de diferentes classes sociais, como a seca expulsa do sertão alguns de seus moradores. Aqui, destacamos o personagem Chico Bento e sua família que, após várias 
tragédias particulares, recebem socorro de Conceição, e então migram para São Paulo. É possível observar nessas obras que muitas vezes a salvação do migrante se dá através de antigas amizades, apadrinhamentos, que levam em consideração suas virtudes trabalhador, honrado, leal, corajoso, honesto.

A lista de obras que tratam das migrações nordestinas é extensa, sua caracterização nem tanto. Na literatura, podemos identificar cerca de três tipos. Primeiro, os romances do século XIX, em que os retirantes protagonistas, geralmente, eram de origem abastada que perdiam tudo por causa da seca. É o caso de Manuel de Freitas, grande fazendeiro, de "A fome" (1890), de Rodolfo Teófilo, que mesmo partindo de suas terras nas mesmas condições de tantos outros, não é igualado aos demais.

Em seguida, destacamos as representações coletivas, uma multidão afligida pela seca, sua caracterização se vincula à própria origem sertaneja, imbuídos dos valores e costumes do sertão, desde meados do século XIX até o início do XX, a questão racial influenciava na representação da imagem do sertanejo, cujos habitantes mestiços, faziam da região um local de bárbaros (SCOVILLE, 2011). Ainda de acordo com esse autor, os retirantes eram tratados como figuras coletivas, de modo negativo, como pessoas que diante de tragédias e fome se tornavam egoístas, brutos, sujos, e capazes de fazer qualquer coisa para saciar a fome, um bom exemplo é a obra "Os retirantes" (1879), de José do Patrocínio, na qual a luta pela sobrevivência torna impiedosos a maioria dos personagens. Em um dos trechos, a personagem Chiquinha ao tentar embarcar no trem e é empurrada pelo chefe da locomotiva que supôs que ela queria embarcar sem passagem. Estatelada no chão, uma multidão de retirantes ri e aplaude o ocorrido.

E, por fim, o migrante pobre e a migrante sensual. "Luzia-Homem" (1903), de Olímpio José, cuja protagonista figura como uma das mais importantes entre os primeiros retirantes pobres, sua história é contada, quando essa migrante já se encontra em seu destino, Sobral, onde trabalha na construção de uma penitenciária e cuida da mãe doente. Mas, já no início da narrativa, várias vezes, são pontuadas as características da multidão de flagelados da seca que chega a cidade. A mulher retirante, que mesmo em meio a uma multidão de flagelados, vestidas em trapos, trazendo no corpo o cansaço e a fome, se tornam objetos de desejo e disputa de diversos homens, como se observa em "Luzia-Homem” (1903), em "Maria Bonita" (1914) e em "A bagaceira” (1928), e, especialmente, na obra de Jorge Amado, "Gabriela", cravo e canela" (1958). 
Apesar de alguma semelhança nos enredos, as personagens retirantes desses romances são essencialmente diferentes. A força e a beleza viril de Luzia em nada se assemelham à beleza inocente de Maria Bonita, tampouco com a malícia, a sensualidade ousada e o jeito abrupto de Soledade. Gabriela, por sua vez, além da beleza reiteradamente posta em evidência, é figurada com uma sensualidade natural mesclada com a absoluta pureza na maneira quase instintiva com que se relaciona com os homens (SCOVILLE, 2011, p. 162).

Após esta breve discussão da representação da migração nordestina na literatura, no cinema, iremos nos ater a duas obras que são, respectivamente, adaptações de produções literárias: "Vidas secas" (1938), escrita por Graciliano Ramos e dirigida, em 1963, por Nelson Pereira dos Santos; e “A hora da estrela” (1977), de Clarice Lispector, adaptada em 1985, por Suzana Amaral para as telonas. O romance de Graciliano Ramos possui 13 capítulos, iniciando com o subtítulo de "Mudança" e terminando com "Fuga", indicando a construção de uma narrativa que representa o ciclo não apenas da seca, mas, junto com ela, o movimento de migração sertaneja, condicionada aos períodos de chuva e estiagem, nesse caso, representados por Fabiano, Sinhá Vitória, a cachorra Baleia e os dois meninos. O filme homônimo seguiu os parâmetros propostos pelo Cinema $\mathrm{Novo}^{2}$, pautado na necessidade de realizar denúncias sociais, tomando o sertão como alegoria.

Foi em uma viagem a Juazeiro (BA), em 1958, que Nelson Pereira teve a ideia de filmar sobre a seca e os retirantes. Os flagelos causados pela longa estiagem lhe serviram de inspiração para retratar o drama vivido pelos sertanejos gracilianos. Ao regressar ao Rio de Janeiro, o diretor releu algumas obras que tinham como tema a seca, como "O Quinze" e "Os Sertões" (1902), de Euclides da Cunha - essa última, vale registrarmos, que serviu e serve de referência para muitos escritores e cineastas quando se trata de representar o Nordeste. Mas, foi a reler "Vidas Secas" que ele não teve dúvidas, tinha em suas mãos um filme (OLIVEIRA, 2016).

Em preto e branco, Vidas Secas inicia sua narrativa, impressionando pela aridez do cenário e pela quantidade de branco na tela, na qual céu e a caatinga são homogeneizados pela luz estourada. Lentamente, distinguimos "pontos negros", movimentando-se na profundidade de campo, que move-se em direção ao horizonte - o espectador, lentamente adquirindo forma humana até aparecer o primeiro ser vivo, a cachorra Baleia, e logo atrás a família de retirantes. Para Ramalho (2016), essa primeira

\footnotetext{
2 Movimento político-cultural, caracterizado por seus aspectos estéticos e políticos comuns aos cineastas que dele faziam parte. Podendo ser visto em três momentos distintos: o primeiro, entre 1955-1964, quando ocorreu a gênese do Cinema Novo; o segundo, entre 1964-1968, quando conheceu seu apogeu e se consolidou como proposta política e cultural; e o terceiro, entre 1969-1973, quando deu espaço às articulações políticas e às propostas individuais (Malafaia, Wolney Vianna, 2012).
} 
caracterização dos personagens, diminuída frente uma apresentação do sertão em vastidão, revela um dos perfis do migrante, um sujeito "engolido" pelo ambiente em que habita, demonstrando assim sua sujeição ao que está lhe impõe. O que chama a atenção é o fato das personagens não serem situadas em um local específico da região, reforçando assim sua condição de perambulantes, fruto de uma dupla exclusão, “(...) pelas condições climáticas infernais e as condições sociais deploráveis, Fabiano prossegue sua marcha de exilado da terra. A partir do momento em que ele não pode comprar nem alugar uma fazenda, seu destino é passar, errar e fugir" (DEBS, 2007, p. 265 apud RAMALHO, 2016, p. 09). O filme chega ao fim do mesmo ponto onde começa, a família na estrada, reforçando mais uma vez a sina do retirante.

Macabéa, personagem central de "A hora da estrela", é, por sua vez, uma retirante alagoana, que migra para o Rio de Janeiro, cidade para a qual nem ela sabe o motivo de ter ido. Semianalfabeta, trabalha como datilógrafa em uma empresa, onde ganha menos de um salário mínimo que só dá para pagar um quarto que divide com mais quatro mulheres e comer cachorro-quente com Coca-Cola, e, às vezes, um sanduíche de mortadela. Contudo, segue a vida sem reclamar de nada. Casualmente, começa um namoro desajeitado com Olímpico, também migrante nordestino, que trabalha de operário metalúrgico. Ele comete alguns furtos e até assassinou um homem no Nordeste. Sempre ríspido com ela, Olímpico a troca por sua amiga Glória, que, na verdade, depois que o seduz e rouba-lhe de Macabéa, por recomendação de uma cartomante, Madame Carlota, desiste da relação amorosa. Na sequência, nossa protagonista consulta também Madame que adivinha-lhe um futuro glorioso.

Adaptada para o cinema em 1985, a obra foi dirigida por Suzana Amaral, que dispensou a mediação do narrador-personagem presente na literatura, cabendo a outros elementos do filme dimensionar a história em volta de Macabéa, interpretada pela atriz Marcélia Cartaxo. Essa diretora também mudou o cenário da narrativa que agora se passa na cidade de São Paulo e uma das principais diversões da nossa protagonista é passear pelos tuneis de metrô nos fins de semana. A fotografia e o figurino fazem questão de evidenciar como a personagem some diante da paisagem cinzenta. A maioria dos ambientes que Macabéa frequenta são poucos iluminados, e em tons tão neutros, quanto suas roupas, representando a frieza da cidade grande. As roupas de Macabéa sempre beges ou cinzas nos transmitem o apagamento da personagem dentro daquele cenário, no qual ela se camufla, mas não pertence. O rosto quase sempre apático, olhos 
voltados para o chão e os ombros curvados em sinal de submissão, nas mais diversas situações, demonstrando sua submissão.

Como podemos perceber, os migrantes representados, ora pela literatura, ora pelo cinema, partem do mesmo ponto: a seca que expulsa os sertanejos. Seus perfis ainda que variados - o fazendeiro que perdeu tudo, o vaqueiro pobre que perdeu o emprego, a retirante sensual ou sem graça como Macabéa, são personagens que ainda que em sua individualidade, acabam representando uma massa de pessoas pobres, mortas de fome, que em alguns casos, devido à brutalidade com que a terra lhe trata, incorpora tal característica e passa a tratar seu semelhante da mesma forma.

As representações sobre os migrantes nordestinos se referem sempre ao deslocamento destes para os grandes centros urbanos como São Paulo, Rio de Janeiro, Fortaleza, etc., sem se preocupar em abordar a possibilidade de retorno desses migrantes para sua cidade natal, e como se dá o encontro entre as novas alteridades tanto do lugar do qual se partiu, tanto do sujeito que retorna com novas bagagens identitárias conquistadas naquele espaço, como veremos a partir de agora com as inquietações da protagonista de $O$ céu de Suely.

\section{Onde fica o lugar mais longe daqui?}

O filme $O$ céu de Suely, de Karim Aïnouz, estreou em 2006, e é o segundo longa-metragem do diretor depois de Madame Satã (2002). A narrativa recebeu alguns prêmios, como "Troféu Redentor", de melhor direção, e melhor filme, no Festival do Rio de Janeiro, bem como "Prêmio da Fipresci", de melhor filme, no Festival Internacional de Salônica, na Grécia. A produção cinematográfica nos conta a história de uma jovem de 21 anos, Hermila (Hermila Guedes), que está de volta a sua cidade-natal, a pequena cidade de Iguatu, que fica no sertão Cearense, com seu filho Mateuzinho. Ela aguarda a chegada do companheiro Mateus, que ficou em São Paulo, mas o tempo passa, e ele não atende mais os telefonemas de Hermila e desaparece. Se sentido desajustada na cidade, a personagem então decide rifar uma noite de sexo com ela, para assim conseguir o dinheiro para comprar passagens de ônibus para o lugar mais longe dali.

Conforme Helcira Lima (2013), a migração dos homens nordestinos sempre é colocada em pauta, seja nas produções literárias ou cinematográficas. O tema ainda 
muito discutido sobre essa saída, as condições de sobrevivência, assim como acerca das dificuldades dos sertanejos em se adaptar à nova realidade das grandes metrópoles. Porém, ainda pouco se discute sobre as mulheres que permanecem no sertão, amparadas pelo dinheiro enviado por companheiros, ou filhos ou ainda na luta diária que elas enfrentam para sobreviver, visto que muitas vezes são abandonadas pelos parceiros. Pensando nesse outro lado da história, Aïnouz em 2004, durante sua estadia em Berlim como bolsista do programa de artistas do Serviço Alemão de Intercâmbio Acadêmico (DAAD), desenvolveu o roteiro do filme, que se chamaria Rifa-me.

Hermilia não permaneceu no sertão, esperando e sendo sustentada pelo companheiro. Ela partiu com ele para São Paulo. O filme inicia ao som de "Tudo que eu tenho", 3 gravada em 1972 pela cantora Diana. As cenas em uma câmera super 8, na qual não dá para ver nitidamente o rosto masculino, nos revela sob a perspectiva de Hermilia que seu idílio amoroso com Mateus. Entre essas imagens de afetos, ela firma que ele a teria dito que a "Faria a mulher mais feliz do mundo". Para Lima (2013), ao fazer da personagem a narradora da cena, o diretor lhe confere o status diferenciado, é ela que narra a própria vida, e a escreverá também, como se perceberá no decorre da trama. $\mathrm{Na}$ sequência seguinte, somos apresentados ao trajeto de volta da personagem, e, através de seu olhar pela janela do ônibus, vemos a paisagem em vários tons de verde. Ela traz no colo o fruto do romance, Mateuzinho.

Ao descer do ônibus com o filho no colo, Hermila se apequena diante da paisagem árida emoldurada na cena (figura 01). O céu ocupa mais da metade do quadro. Em outras cenas, podemos notar o mesmo enquadramento dado a esse elemento, dentro da narrativa, há várias interpretações que se pode dar a esse céu. Para Sandra Ficsher (2010), a presença do céu no filme pode ser lida no sentido de opressão, remetido através das vastas larguras horizontais que realçam a escassez de residências. Assim, temos poucos interiores, para contrastar com o excesso de exteriores, revelando paisagens que não oferecem abrigos e sufocam transmitindo pelo calor laranjaavermelhado, que emana do azul que onde a maioria dos planos externos foi feita de modo que o céu apareça e até domine o quadro, como, por exemplo, nas cenas que mostra o amanhecer em que os tons azuis se sobrepões aos acinzentados do dia em Iguatu, ou na cena em que Hermila está à beira da estrada e emanam do azul os tons laranja-avermelhado do pôr do sol. Ressaltamos, que o azul é a cor mais quente entre as

\footnotetext{
${ }^{3}$ Versão em português da canção Everything I Own (1972), escrita por David Gates.
} 
cores, e ele se espalha por toda a composição fílmica, pelos figurinos dos personagens, no interior da casa e no local de trabalho da avó de Hermila (Zezita Matos), reforçando a sensação de opressão e sufocamento.

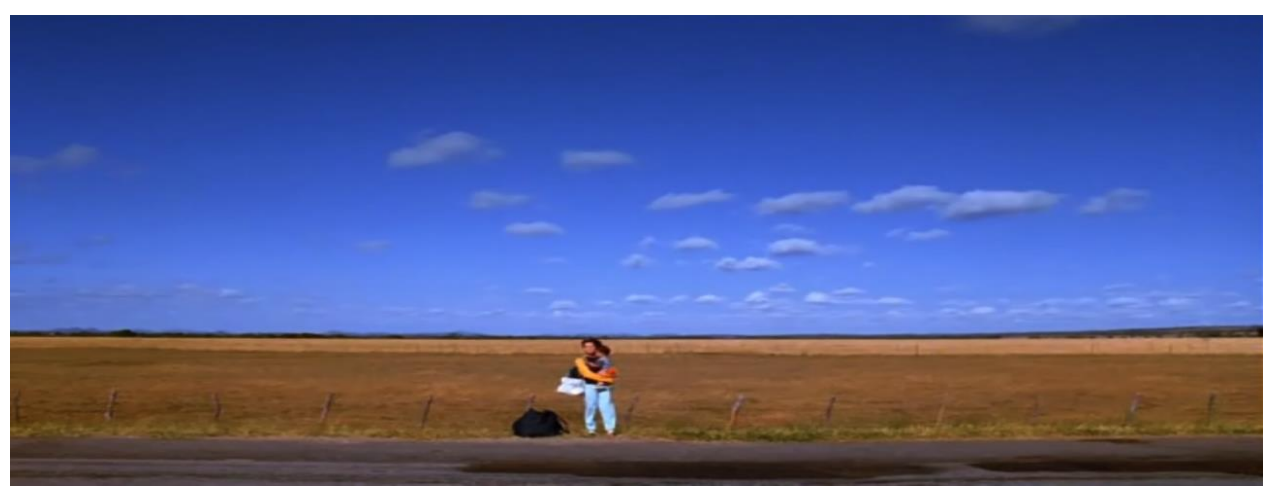

(Figura 01)

A Iguatu não ficcional e que se orgulha de ter sido cenário para o filme, ostentando a afirmação da história cinematográfica ter sido inspirada em uma narrativa verdadeira, é uma cidade banhada pelo Jaguaribe, um dos principais rios cearenses. Esse foi um dos primeiros municípios do Ceará a se desenvolver, a partir da produção de algodão, e, hoje, sua economia é baseada na agricultura (plantio de arroz, banana, feijão, milho), na pecuária e no comércio. O desenvolvimento industrial ainda é lento, mas, dentre algumas indústrias já se encontram de produtos alimentares, vestuário, calçados e artigos de tecido e couro. Entre seus pontos turísticos está a Ponte Metálica da Estrada de Ferro, construída em 1916 pela South American Railway Company ${ }^{4}$.

Por uma escolha estética e ideológica do diretor, para dar uma maior dramaticidade ao enredo fílmico, o que acaba por reforçar uma imagem das cidades do interior como desertas e subdesenvolvidas, a Iguatu de Aïnouz é apenas um lugar no interior do Ceará, onde os enquadramentos nos sugerem uma posição geográfica isolada no meio sertão, sendo cortada pelas rodovias e por uma linha férrea, tendo como mais novo point um posto de gasolina, Veneza. Tais elementos funcionam como uma alegoria nos indicando Iguatu como um lugar de passagem. A mesma rodovia que traz e leva Hermila, por exemplo, é usada pelos caminhões de carga que vemos em cena, cruzando a estrada ou pernoitando no posto de gasolina, mas que logo devem seguir viagem. O trem que passa pela cidade apitando e quebrando a rotina do lugar corrobora

\footnotetext{
${ }^{4}$ Informações disponíveis no site da Prefeitura Municipal de Iguatu: http://iguatu.ce.gov.br/a-cidade/.
} 
nesse sentido também. Lembremos que, os trens, entre os séculos XIX e XX, eram uma das principais formas de transportarem os migrantes para fora do Nordeste, especialmente para a região Norte durante o ciclo da borracha.

Segundo Lima (2013), apesar de Iguatu estar longe de tudo, a cidade não está de todo alheia ao que acontece no resto do mundo, traços também de um lugar de passagem, onde a fluidez de pessoas deixa rastros de informações. Por isso, tantos horizontes e estradas, sem começo ou fim, representam uma impossibilidade de delimitar fronteiras. Ideia que o diretor busca passar também, através da trilha sonora, com músicas dos mais variados estilos, pop, brega, forró eletrônico, utilizando versões brasileiras das músicas Everything I Own, conhecida na voz de Boy George, no Brasil, como "Tudo que eu tenho", na voz de Diana e a música Torn, na voz de Natalie Imbruglia, cantada pela banda Aviões do Forró com o título de "Blábláblá" e a música "Eu não vou mais chorar", também cantada por esse grupo. Essas músicas representam o tráfego de informações e referências que revelam uma nova dinâmica mundial, da qual nenhuma cidade está realmente isolada, onde local e global se conectam.

As músicas também funcionam como elemento narrativo das situações enfrentadas pela personagem. Na cena inicial, Lima (2013) ressalta que a música "Tudo que eu tenho", salienta a impressão de deslocamento e suspensão do fato que será o estopim para a história. Mesmo sendo uma cena romântica, e Hermila falando sobre momentos de felicidade ao lado do companheiro, a letra da canção nos remete a um tempo passado, um prenúncio do futuro rompimento amoroso e dos sonhos de nossa personagem. Como podemos conferir:

\footnotetext{
Que bom seria ter seu amor outra vez/Você me fez sonhar/Trouxe a fé que eu perdi/E nem eu mesma sei porque/Eu só quero amar você/Tudo que eu tenho meu bem é você/ Sem seu carinho eu não sei viver/Tudo que eu tenho meu bem é você/Volte logo meu amor/Eu tento esquecer/Que você já foi meu/Nunca mais eu vou achar um outro amor/E nem vou procurar/Não quero amar a mais ninguém/Como você não há ninguém/Tudo que eu tenho meu bem é você/Sem seu carinho eu não sei viver/Tudo que eu tenho meu bem é você/Volte logo meu amor/Se você não voltar vou sozinha ficar/Solidão vai morar comigo/Vou viver infeliz/Pois o que sempre eu quis/Foi viver contente sempre ao lado seu.
}

Após ser deixada por Mateus, a canção agora é alegre, um forró eletrônico, “Eu não vou mais chorar”, a qual ela canta junto com Jéssica em um karaokê:

Eu não vou mais chorar/Eu não vou mais chorar/Sofro até te esquecer/Mas não vou mais chorar/Eu não vou mais chorar/Você só me fez sofrer/Amor, vou te deixar/Mas não vou chorar/Vai doer em $\mathrm{mim} /$ Sempre que lembrar/Todos os momentos que eu tive com você/Ficarão pra sempre dentro 
do meu coração/Sei que não vai ser fácil pra mim te esquecer/Mas ficar chorando por você/Choro mais não.

Em sua pesquisa sobre as representações de gênero no forró eletrônico, Rios (2015), aponta a banda Aviões do Forró como umas das principais personagens no cenário do forró eletrônico da atualidade. O grupo era composto pelos integrantes Solange Almeida e José Alexandre (Xand Avião), todavia essa cantora deixou a banda no início de 2017 para seguir em carreira solo e os produtores decidiram por não substituir a voz feminina, ficando apenas Xand à frente da banda. Na análise das músicas desse grupo musical, entre os anos de 2000-2005, a autora demonstra que as letras falavam de homens sensíveis que sentiam na pele as alegrias e as tristezas do amor. Homens que sofrem por amor, e, em um número menor, aqueles que são realizados na relação. Sobre a referida música, Rios (2015) destaca a descrição de um homem ainda dividido com sentimentos contraditórios sobre a mulher que o decepcionou, triste pelo rompimento, mas ainda a chamando de amor, "Sua insegurança é tão grande, que ele repete várias vezes que não vai mais chorar, como que numa tentativa de convencer a si mesmo do que está dizendo" - "Eu não vou mais chorar" (p. 10).

Em certo momento na trama escrita por Antônio Torres em 1976, "Essa Terra", Totonhim declara que o sertão é uma sina. Dele sempre se vai, mas para ele sempre se volta, é um lugar de “Ir e vir, vir e voltar”, o filme $O$ céu de Suely nos passa essa sensação. Hermila volta de São Paulo, se instala novamente em Iguatu, e enquanto não vai embora novamente da cidade, por diversas vezes, o diretor coloca a personagem na estrada para metaforizar a condição da personagem como migrante. Caminhos que, como podemos perceber, dão a ideia de longas distâncias a serem percorridas. Hermilia praticamente desaparece em meio a paisagem, onde se sobressaem o fundo de céu azul e poucas casas e a luz estourada, assim como no filme Vidas Secas.

Ressaltamos ainda, uma imagem em que a paisagem terrestre ocupa a maior parte do quadro, o início de um caminho, que, pelo que percebemos, é um entroncamento para uma outra estrada, onde a protagonista quase nem aparece, o que chama nossa atenção na composição dessa cena (figura 02). A estrada, segue a mesma lógica. Na sequência, a câmera está mais próxima da personagem que está à beira da rodovia, procurando um brinco. O céu aqui parece arder em chamas ao pôr-do-sol, a autopista asfaltada aqui também se destaca, ocupando grande parte do quadro, como 
mais uma estrada das muitas que aparecem no filme, as quais a protagonista sempre está em volta (figura 03 ).

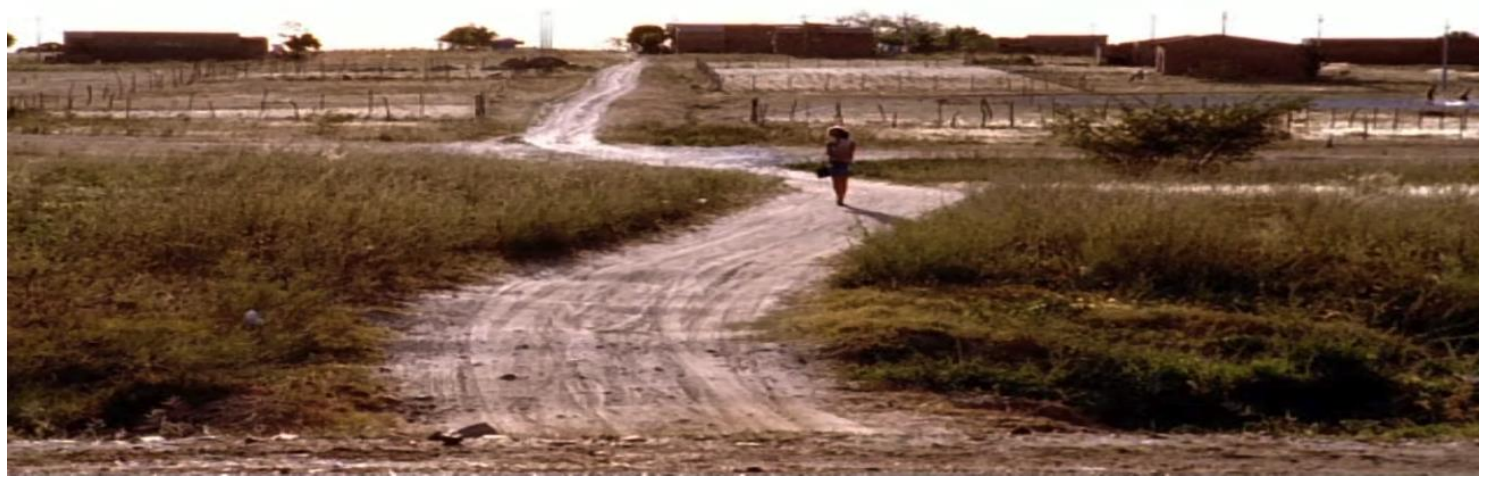

(Figura 02)

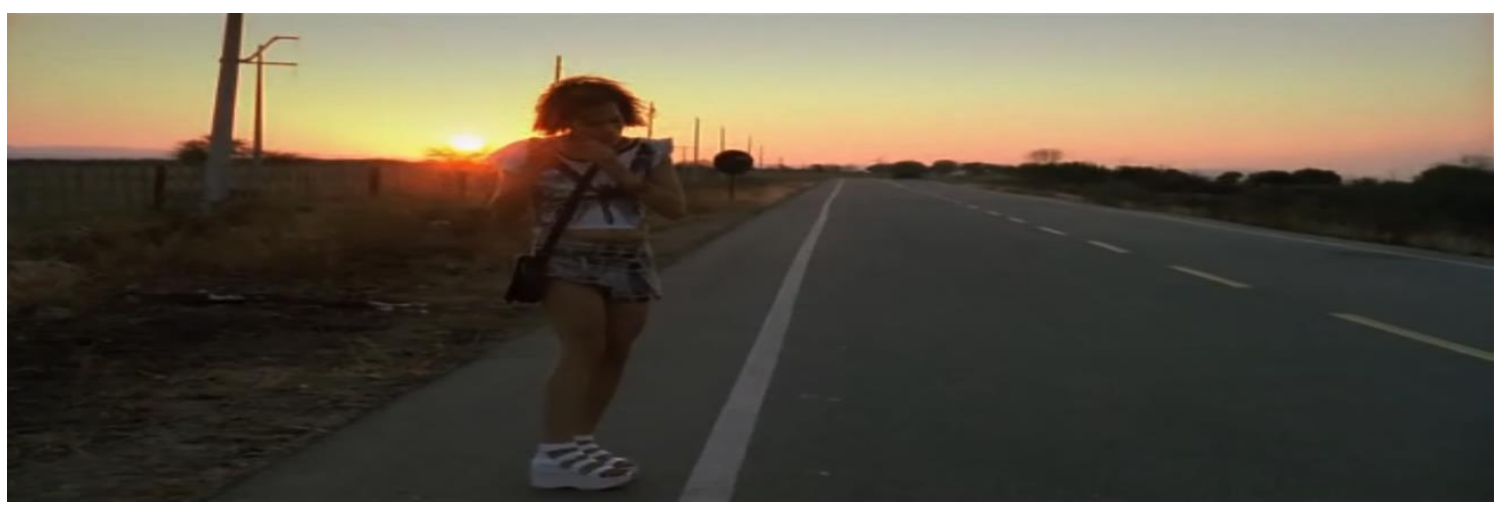

(Figura 03)

Esse ir e vir de Hermilia nos revela outro aspecto importante, a inadequação ao lugar ao qual se retorna, a fragmentação da ideia de que nos identificamos com o lugar ao qual pertencemos. Para Hall (2013), no retorno, muitos migrantes sentem que a terranatal tornou-se, de certo modo, desconhecida, como se os elos que tidos como naturais e espontâneos que possuímos, tivessem sido cortados, um efeito causado pelas experiências vivenciadas nas diásporas que mudam a história de forma irrevogavelmente. Nesse contexto, quando a protagonista, em determinado momento da narrativa vai à rodoviária e pergunta qual o lugar mais distante de Iguatu, o que fica evidenciado é que a questão ali não se trata sobre uma cidade específica, mas sim sobre fugir daquele lugar, considerado por Hermila fonte de sua miséria, não apenas material, mas emocional, pela qual ela passava, por não mais se encaixar naquela sociedade. Se é que algum dia se encaixou. 
Assim a protagonista adota o codinome Suely, quando decide rifar o próprio corpo, para conseguir o dinheiro necessário para ir para longe, mas o texto fílmico deixa claro que nem Hermilia nem Suely são putas, já que se deitará apenas com um homem, uma fala que revela um pensamento comum na sociedade, de que "mulher séria" aquela com a qual o homem pode relacionar-se - é a que tem poucos ou apenas um parceiro sexual, como se a honestidade e a honradez da mulher fosse exprimida através de sua sexualidade. De acordo com Manuela Cunha Peixinho (2015), a forma como as mulheres que optam pela prostituição acham para conciliar essas "duas mulheres" é assumir um outro nome, de um lado oculta, ainda que debilmente, já que o rosto está exposto, sua identidade fora do ambiente da prostituição, de outro constitui uma a criação de uma personagem, a qual atuará nos gestos, na fala, em ações propicias a exigência da situação.

Embora a rifa seja um sucesso, em duas cenas, Hermila é agredida pelo prêmio que oferece, salientando que mesmo adotando outro nome, esse é um artificio frágil, que não a protege. Em uma delas, uma mulher a coloca contra a parede de uma loja, chamando-lhe de Suely, ela rebate dizendo que se chama Hermila, mas essa personagem continua acusando-a de puta e se referindo ao fato de seu cunhado ter comprado um bilhete, e fazendo-lhe ameaças. Por fim, a protagonista admite a situação, justificando que a culpa não seria dela, mas do homem casado que comprou a rifa. A outra mulher ignora esse fato e retira-se do quadro.

Essa sequência apresenta um fato importante a ser ressaltado: a culpabilização social da mulher, especialmente, quando essa se envolve com homens casados. O sexo masculino, geralmente, é vitimizado, enquanto as mulheres são demonizadas, elas que seduziram, roubaram o homem da "mulher de valor". Segundo Lima (2013), é desse modo que a imagem de Hermila se arquiteta não apenas através de suas palavras e por seu comportamento transgressor, mas, principalmente, por seu corpo: “A ideia da rifa parece, assim, consistir em um importante elemento para a compreensão dessa personagem. Isto porque o corpo tem uma história: ele é representação e lugar de poder, vale dizer, de inscrição do poder” (p.133). Apesar dessa perspectiva machista e opressora sobre Hermila, $O$ céu de Suely também é sinônimo de paraíso, uma vez que, por dar uma conotação sexual positiva, de valorização e emancipação do feminino. Quando a protagonista anuncia o prêmio da rifa: "Uma noite no paraíso", que o ganhador da rifa terá como prêmio, ou seja, uma noite de sexo e prazer com seu alter ego Suely, ela está se (re)apropriando de seu próprio corpo, principalmente se 
considerarmos que não há por trás dela um homem capitalizando os recursos da venda dos bilhetes, como, normalmente, em casos de prostituição é comum.

Quanto ao seu desejo de sair da cidade, podemos perceber nas cenas finais, quando Hermila deixa Iguatu que, mais uma vez o céu azul sem nuvens domina o quadro (figura 04). Uma placa indica que ali é saída da cidade, onde "Começa a saudade de Iguatu". No ônibus, a câmera em close nos mostra o olhar da protagonista que observa João (João Miguel) na motocicleta acompanhando o ônibus. Os dois veículos desaparecem no horizonte. Então, a metáfora se concretiza, a estrada que leva para fora de Iguatu toca o céu e Hermila conquista seu paraíso: o sonho de sair da cidade.

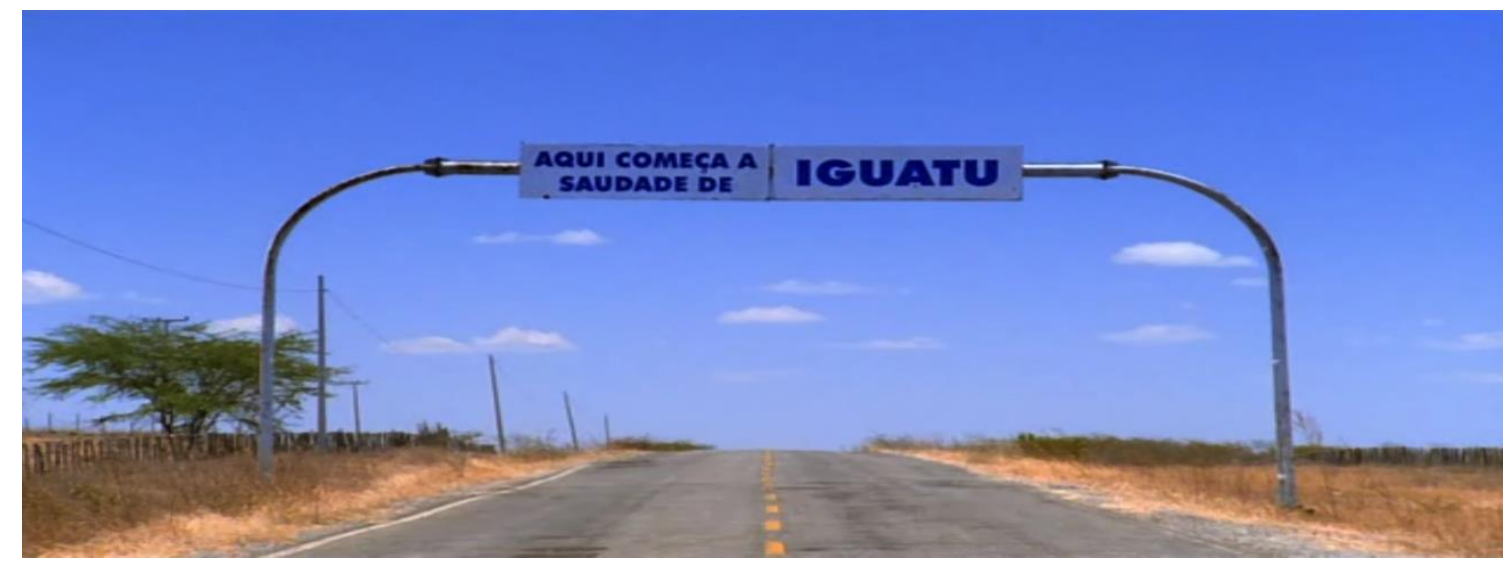

(Figura 04)

\section{Considerações finais}

A obra cinematográfica de Karin Aïnouz, traz uma nova perspectiva sobre a migração nordestina. Hermila e Mateus não saem de Iguatu expulsos pela seca, diferente de obras literárias e cinematográficas, que marcaram os séculos XIX e XX. As migrações nordestinas sempre foram representadas pela busca de uma vida melhor, que o sertão jamais seria capaz de oferecer, principalmente, devido às secas. Assim, muitos sertanejos enfrentam o rompimento de suas raízes e chegam a um novo local, onde ocorrem cruzamentos socioculturais dos mais diversos, que resultam em uma nova configuração identitária.

Esse vínculo entre o sujeito e o lugar - isso inclui não apenas o espaço territorial, mas a toda sua constituição cultural - implica em uma construção bilateral e recíproca (CASEY, 2001). Assim, migrar para outro lugar ou o retorno desse migrante as suas origens envolvem relações de poder, não apenas das relações de força entre 
regiões, mas também de processos sociais. Hermila é assim, o canal, pelo qual podemos observar como o processo de migração é ao mesmo tempo concreto e simbólico, mediado pelo espaço, ou seja, a migração impele os indivíduos a gerir o universo cultural que lhe foi dado ao nascer e negociá-lo com àquele no qual está se inserindo, ocorrendo daí entrecruzamentos entre valores, que farão surgir novos valores para a adaptação ao novo ambiente.

O filme nos revela os dilemas pelos quais a grande maioria daqueles que retornam a sua cidade/região natal passam. Entre eles, o desencaixe que a protagonista sente em seu retorno para Iguatu. Tudo ali lhe incomoda, desde o lugar e o calor que nele faz, desde o modo de pensar das pessoas. No processo migratório de Hermila, os novos valores, que surgiram na sua adaptação no espaço paulista, não se encaixam naquela cidade, onde aparentemente algumas coisas mudaram, mas não foram suficientes para conformar a nova identidade da personagem.

Aïnouz acerta ao problematizar o retorno dessa migrante a seu local de origem, o que pode parecer, a princípio, ofertar ao migrante a chance de reconstruir e resgatar os laços não apenas afetivos, mas identitários que sofreram desgastes com a distância, representando muitas vezes uma crise de identidade. $\mathrm{O}$ diretor demonstra como esse retorno traz consigo as marcas de uma nova identidade, que, muitas vezes, já não entra em acordo com o que encontra, nada é mais simplesmente o que se encontra na memória, nem o espaço, nem o sujeito.

\section{Referências}

ALBUQUERQUE JÚNIOR, Durval Muniz de. A Invenção do Nordeste e outras artes. Recife: FJN, ed. Massangana; São Paulo: Cortez, 1999.

Nordestino: a invenção do falo - Uma história do gênero masculino. Maceió: Edições Catavento, 2003.

BORGES, Tânia Cristina Souza. "A culpa é minha" ou "A hora da estrela?": uma análise do romance a hora da estrela de Clarice Lispector. 2014. 97 f. Dissertação (Mestrado em letras) - Universidade de são Paulo.

BOTEGA, Tuíla. Migração de Retorno e Crise: Sonho frustrado?. Centro Scalabriniano de Estudos Migratórios - CSEM. Disponível em: http://www.csem.org.br/images/downloads/artigos/Migra\%C3\%A7\%C3\%A3o_de_retor no_e_crise_sonho_frustrado.pdf. Acesso em: 05/05/2017. 
in the Place-World? Annals of the Association of American Geographers. v. 91, n. 4, p. 683-693, 2001. Disponível em:

https://philosophydocuments.files.wordpress.com/2014/11/22-geography-place.pdf.

Acesso em: 28/07/2017.

COSTA, Antônio. Compreendendo o cinema. São Paulo: Globo, $3^{\text {a }}$ ed., 2003.

DANTAS, Sylvia Duarte; UENO, Laura. LEIFERT, Gabriela et. al. Identidade, migração e suas dimensões psicossociais. Brasília, v. 45. n. 34, p. 45-60, jan./jun. 2010. Disponível em: http://www.csem.org.br/remhu/index.php/remhu/article/view/208. Acesso em: 02/05/2017.

FISCHER, Sandra. Azuis de Ozu e De Aiïnoz: clausura e deslocamento. Estudos de cinema e audiovisual Socine. São Paulo: Socine. v. 10. p. 714. p. 2010. Disponível em: http://www.socine.org.br/livro/x_estudos_socine_b.pdf. Acesso:

FUSCO, Wilson; OJIMA, Ricardo. Migrações e nordestinos pelo brasil: uma breve contextualização. In: Migrações Nordestinas no Século 21: um Panorama Recente. (Orgs.) Ricardo Ojima; Wilson Fusco. Editora Edgard Blücher Ltda. 2014. Disponível em: http://pdf.blucher.com.br.s3-sa-east-1.amazonaws.com/openaccess/migracoesnordestinas/completo.pdf. Acesso em: 06/02/2017.

HALL, Stuart. Da diáspora: Identidades e mediações culturais. Org. Liv Sovik. Belo Horizonte: Editora UFMG, 2013. $2^{\text {a }}$ Ed, 434 p.

A identidade cultural na pós-modernidade. Trad. Thomaz Tadeu da Silva. 7

a ed. Rio de Janeiro: DP\&A Editora, 2003.

JOLY, Martine. Introdução à análise da imagem. Campinas, São Paulo, 1996.

LIMA, Helcira. O céu de Suely: contornos do feminino. In: Representações do feminino no cinema brasileiro. Org. Helcira Lima. FALE/UFMG Belo Horizonte 2013. Disponível em:

http://150.164.100.248/vivavoz/data1/arquivos/representacoes_feminino_site.pdf Acesso em: 31/04/2016.

MALAFAIA, Wolney Vianna. Imagens do Brasil: o Cinema Novo e as metamorfoses da identidade nacional. 2012. 316 f. (Doutorado em em História, Política e Bens Culturais) - Centro de Pesquisa e Documentação de História Contemporânea do Brasil - CPDOC, Rio de Janeiro. Disponível em:

http://bibliotecadigital.fgv.br/dspace/bitstream/handle/10438/10244/Introdu\%C3\%A7\% C3\%A3o.Cap.I.II.III.IV.Conclus\%C3\%A3o.2012-1.pdf? sequence=3.

Acesso em: 31/04/2016.

MARTIN, Marcel. A Linguagem Cinematográfica. São Paulo: ed. Brasiliense, 2003.

OLIVEIRA, Vanessa da Luz. Signos de nordestinidade: análise da representação da identidade do vaqueiro no cinema brasileiro no período de 1960 a 1990. Relatório técnico final. 2016.31f. 
PAIVA, Carla Conceição da Silva. A virtude como um signo primordial da nordestinidade: análise das representações da identidade social nordestina nos filmes $\mathrm{O}$ Pagador de Promessas (1962) e Sargento Getúlio (1983). 2006 - 115 f. Dissertação (Mestrado em educação) - Universidade do Estado da Bahia - UNEB, Salvador.

Mulheres nordestinas, sujeitos ou objetos? Análise da representação feminina em quatro filmes brasileiros da década de oitenta. 2014. 317 f. Tese (Doutorado em Multimeios) - Universidade Estadual de Campinas.

RAMALHO, João Pedro. Signos de nordestinidade: análise da representação da identidade do migrante nordestino no cinema brasileiro no período de 1960 a 1990.

RIOS, Daniele Moitinho Dourado Valois. É festa, amor e sexo? Um estudo sobre as representações de gênero no forró eletrônico. 2015. 135 f. Dissertação (Mestrado em Comunicação) - Universidade Federal de Pernambuco.

SANTOS, Maria de Fátima de Souza; ALMEIDA Leda Maria de (org.). Diálogos com a teoria das representações sociais. Recife: Ed. Universitária da UFPE/Ed. Universitária da UFAL, 2005.

SCOVILLE, André Luiz Martins Lopez de. Literatura das secas: ficção e história. 2011. 241 f. Tese (Doutorado em Letras - Estudos Literários) - Universidade Federal do Paraná. Disponível em:

http://acervodigital.ufpr.br/bitstream/handle/1884/26633/Andre\%20Scoville\%20$\% 20$ Tese $\% 20$ Literatura $\% 20$ das $\% 20$ secas $\% 20-\% 20$ versao $\% 20$ final.pdf?sequence $=1$ Acesso em: 08/04/2017.

SILVA, Tomaz Tadeu da. Identidade e diferença: a perspectiva dos estudos culturais. Petrópolis, RJ: Vozes, 2000.

TORRES, Antônio. Essa Terra. São Paulo: Ática, 1991.

VANOYE, Francis; GOLIOT-LÉTÉ, Anne. Ensaio sobre a análise fílmica. Trad. Marina Appenzeller. Campinas, São Paulo: Papirus, 1994.

VICTOR, Keicy; GALINDO, Marco; RABAY, Glória. A Metamorfose de Hermila: A Migração Nordestina e as Relações de Gênero no Filme O Céu de Suely. In: Rede Feminista Norte e Nordeste de Estudos e Pesquisa sobre a Mulher e Relações de Gênero - REDOR. Recife -PE, 24-27 de novembro 214. Disponível em: http://www.ufpb.br/evento/lti/ocs/index.php/18redor/18redor/paper/view/1971 Acesso: 08/04/2017.

VILLA, Marco Antônio. Quando eu vim me embora: história da migração nordestina para São Paulo / Marco Antônio Villa. - Rio de Janeiro: LeYa, 2017. 224 p. 